\title{
AMCP Partnership Forum: Digital Therapeutics-What Are They and Where Do They Fit in Pharmacy and Medical Benefits?
}

\begin{abstract}
SUMMARY
Digital therapeutics (DTx) - software that delivers a clinical mechanism of action, either alone or in combination with other standard-of-care treatments to improve outcomes-is an emerging class of therapeutic interventions that poses many questions for the health care system. To examine the systems and processes that will support the adoption and utilization of DTx, AMCP convened a multidisciplinary stakeholder forum September 17-18, 2019, in Alexandria, Virginia. The goals of the forum were to (a) describe DTx and how managed care organizations evaluate their value; (b) identify where DTx fits within a covered benefit; (c) outline evidentiary standards needed for coverage of DTx; and (d) outline how payers and managed care organizations may leverage DTx for value-based care and patient engagement. Health care leaders representing academia, health plans, integrated delivery systems, DTx manufacturers and industry leaders, pharmaceutical manufacturers, pharmacy benefit managers, employers, federal government agencies, national health care provider organizations, and patient advocacy organizations participated in the forum.

Participants identified characteristics of DTx to develop a better understanding of the spectrum of solutions and how they are distinct from other digital health products, such as mobile health devices, monitoring, care coordination, or electronic health records. The evidence needed to evaluate DTx will likely be tiered based on its medical claim or function and should align with standards for clinical evidence. Clinical evidence must be evaluated by appropriate health authorities (e.g., the U.S. Food and Drug Administration) and receive market authorization (e.g., clearance, approval) with a regulatory label.

Various benefit coverage options were discussed. While some participants suggested that the unique features of DTx could be best addressed by a novel digital benefit, others argued that creating an additional benefit would result in further health care system fragmentation. They observed that the increasing focus on compensating providers for outcomes supports integrating DTx within existing benefit structures. They noted that some DTx might be more appropriate for the medical benefit and others might be better aligned with the pharmacy benefit. Finally, many participants observed that, while additional DTx-specific education may be needed, pharmacists are trained to have the knowledge and skills that make them well suited to play a key role in guiding appropriate use of DTx.
\end{abstract}

J Manag Care Spec Pharm. 2020;26(5):674-81

Copyright $\odot 2020$, Academy of Managed Care Pharmacy. All rights reserved.

$\mathrm{D}$ igital therapeutics (DTx)—software that delivers a clinical mechanism of action, either alone or in combination with other standard-of-care treatments to improve outcomes-is an emerging class of therapeutic interventions that poses many questions for the health care system. DTx represents one segment of digital health products and can be distinguished from other products, such as mobile health (mHealth) products or wearable devices, specifically by their demonstrated impact on measurable clinical outcomes. DTx, either as standalone products or for use in conjunction with other treatments, is emerging as a novel treatment modality for a wide range of health conditions. Several have been approved by the U.S. Food and Drug Administration (FDA) for use by patients with various disease states including diabetes, asthma, depression, and substance use disorder. For example, reSET was approved by the FDA for the treatment of substance use disorder. DTx products have a spectrum of different potential functions, including modifying use of medications, modifying patient behavior independent of the use of a pharmaceutical product, and treating a medical condition or affecting the underlying physiological response of the patient. Many also have the capacity to provide data to health care providers.

Generally speaking, characteristics of therapeutic areas that are good targets for DTx include the following:

- Chronic conditions needing frequent, high-touch therapeutic interventions

- Diseases without existing treatments or treatments with elevated risk of side effects (unmet medical needs)

- Complex diseases and diseases for which existing treatments can be enhanced with software

- Diseases that could benefit from increased interaction, for example to support adherence or to track patient data to enable a treat-monitor-treat loop

- Diseases associated with stigma that may affect patient willingness to interact with health care providers

Providers and other stakeholders are using digital health technologies in their efforts to reduce inefficiencies, improve access, reduce costs, increase quality, and make medicine more personalized for patients. ${ }^{1}$ DTx has the potential to transform the delivery of health care by allowing for remote patient engagement, better capture and tracking of outcomes, virtual health monitoring to inform treatment, and coaching.

Several market forces are supporting the development and use of DTx. For example, patients are increasingly using digital channels to engage with their health and health care providers, with a high level of patient and caregiver interest in smartphone apps that are designed to affect health. As the health care system increasingly focuses on value and outcomes, DTx allows providers to monitor and intervene with patients between visits and also allows for capturing and tracking data that can be used to evaluate outcomes.

As this emerging product category develops, it poses many challenges and opportunities for the health care system. Adaptations of the existing infrastructures for the delivery of health care products and services will be needed to establish a framework that facilitates optimal utilization of DTx. How does DTx differ from existing digital products in the health care 
TABLE 1 Categories of Digital Health Products that Are Not DTx

\begin{tabular}{|c|c|c|c|}
\hline Category & Description & Delivery & Examples \\
\hline mHealth & $\begin{array}{l}\text { mHealth is the practice of medicine and public health } \\
\text { supported by mobile devices }\end{array}$ & $\begin{array}{l}\text { Software } \\
\text { via a mobile } \\
\text { device }\end{array}$ & $\begin{array}{l}\text { - Clinician-facing: Mobile medical applications; an extension } \\
\text { of a medical device; or displaying, storing, analyzing, or } \\
\text { transmitting patient-specific medical device data } \\
\text { - Consumer-facing: Lifestyle, fitness tracking, nutrition, and } \\
\text { medication adherence apps }\end{array}$ \\
\hline HIT & $\begin{array}{l}\text { HIT is information technology applied to health and health } \\
\text { care. It supports health information management across } \\
\text { computerized systems and the secure exchange of health } \\
\text { information between consumers, providers, payers, and } \\
\text { quality monitors }\end{array}$ & $\begin{array}{l}\text { Software or } \\
\text { platform }\end{array}$ & $\begin{array}{l}\text { - Electronic medical record systems } \\
\text { - Electronic prescribing system } \\
\text { - Consumer health interface (e.g., MyChart) }\end{array}$ \\
\hline $\begin{array}{l}\text { Devices, } \\
\text { sensors, } \\
\text { wearables }^{a}\end{array}$ & $\begin{array}{l}\text { Devices that can be worn, attached on skin, or ingested to } \\
\text { continuously and closely monitor an individual's activities, } \\
\text { without interrupting or limiting the user's motions. These } \\
\text { devices are supported by embedded technology for data } \\
\text { communication and sensors to interact with both internal } \\
\text { and external objects and the environment }\end{array}$ & $\begin{array}{l}\text { Hardware } \\
\text { and software }\end{array}$ & $\begin{array}{l}\text { - Wearable and wireless devices, (e.g., Fitbit, Apple Watch) } \\
\text { - Biometric sensors } \\
\text { - Diagnostic products } \\
\text { - Proprietary algorithms that control the function of physical } \\
\text { devices, such as insulin pumps }\end{array}$ \\
\hline Telehealth & $\begin{array}{l}\text { The provision of health care remotely by means of } \\
\text { telecommunications technology }\end{array}$ & $\begin{array}{l}\text { Software or } \\
\text { platform }\end{array}$ & $\begin{array}{l}\text { - Telehealth platform } \\
\text { - Telemedicine platform }\end{array}$ \\
\hline
\end{tabular}

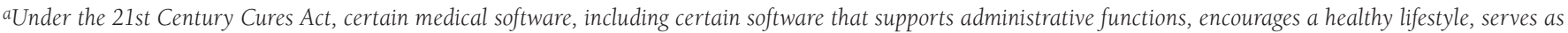

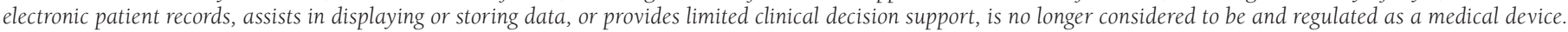
DTx= digital therapeutics; HIT = health information technology; $m$ Health = mobile health .

space? What role does DTx play in managing a medical condition, preventing a disorder or disease, optimizing medication use, or treating a disease or disorder? What are the evidentiary standards needed for third-party payer coverage of digital therapeutics? What types of reimbursement and contracting arrangements are appropriate? And where do they fit within pharmacy and medical benefits?

\section{Describing Digital Therapeutics}

The broad scope of digital health includes categories such as mHealth and health information technology (HIT), which include electronic health records (EHRs), wearable devices, and telehealth. ${ }^{2}$ The World Health Organization has developed a classification system to define various types of digital health products. ${ }^{3}$ Categories of digital health products that are not considered DTx are listed in Table 1.

DTx can be designed to stand alone or work in combination with existing medications or treatments, helping patients manage their therapies and ensuring the therapy delivers the best outcomes possible. In general, participants agreed that the key distinguishing feature of a DTx is that it makes a health claim that is validated by a third party (e.g., a regulatory authority).

Participants described the features of DTx to achieve common understanding and nomenclature of what constitutes a DTx and what differentiates DTx from other digital health products (Table 2). Key characteristics of DTx that were identified include a general description, approval and validation processes, and levels of evidentiary standards for safety and efficacy to support regulatory approval and coverage by payers.
Other features that are important include patient access, product delivery, product and billing coding, and reimbursement.

\section{Evidence Requirements for DTx Approval}

Regulatory Approvals. Approval and/or market authorization by a regulatory body, such as the FDA, is necessary for market entry and is important for approval for coverage or inclusion on a formulary by a payer. Regulatory requirements (such as those provided by the FDA) and industry alliances provide standards for validating DTx, with the focus on protecting patients and providing assurance of evidence. ${ }^{4}$ Levels of evidence should correspond to existing standards used across health care and medicine. ${ }^{5}$ Participants identified various considerations for the type of evidence preferred by various stakeholders. However, participants noted that different levels of evidence could be appropriate for different products in a risk-adjusted manner, as is common for other therapeutic modalities (Table 3). They stressed that the rigor of evidentiary requirements should be tiered based on factors such as the medical claims being made and safety considerations associated with the DTx. For example, a product that makes a claim that it could replace a pharmaceutical product may be required to comply with evidentiary standards similar to those for the pharmaceutical product it is replacing.

The types of evidence required for regulatory approval were explored. Participants noted that the 21st Century Cures Act of 2016 made changes to allow some DTx to be reviewed and approved by the FDA through the 510(k) regulatory pathway; some DTx have already been approved through this pathway. The $510(\mathrm{k})$ pathway allows manufacturers to demonstrate 


\section{TABLE 2 Features of Digital Therapeutics Identified by Forum Participants}

\begin{tabular}{|c|c|}
\hline Feature & Details \\
\hline Description & - Interventions that are driven by software programs to prevent, diagnose, manage, or treat a medical disorder or disease \\
\hline $\begin{array}{l}\text { Approval or validation } \\
\text { process/regulation }\end{array}$ & $\begin{array}{l}\text { - Impartial third-party provides premarket validation of efficacy, clinical effectiveness, safety, data security, privacy, and quality by } \\
\text { regulatory or equivalent national body } \\
\text { - Level of regulation should be dependent on the risk-benefit analysis of the therapeutic claim and potential for harm } \\
\text { - In the United States, the FDA is responsible for products making therapeutic claims, guided by the SaMDa framework and } \\
\text { developed by the International Medical Device Regulators Forum } \\
\text { - DTx may fall under the De Novo, } 510(\mathrm{k}) \text { regulatory pathway for DTx and NDAs, including } 505(\mathrm{~b})(2) \text { for combination products } \\
\text { - Other regulatory bodies may also be involved }\end{array}$ \\
\hline Evidence & $\begin{array}{l}\text { - Clinical trials and ongoing evidence generation required for safety and efficacy } \\
\text { - Standard tiered levels of evidence required based on claims } \\
\text { - Pragmatic trials in real-world settings } \\
\text { - User experience testing }\end{array}$ \\
\hline $\begin{array}{l}\text { Safety and } \\
\text { efficacy claims }\end{array}$ & - Appropriate to clinical validation and regulatory status \\
\hline Patient access & $\begin{array}{l}\text { - Nonprescription or prescription, depending on clinical use; the potential to cause harm; risks, safe use potential, or product claims } \\
\text { - Could be distributed through various channels, including community pharmacies, specialty pharmacies, and patient service cen- } \\
\text { ters, as well as app stores or similar portals and websites of providers, payers, or employers } \\
\text { - Consider whether it is a patient-facing DTx only or works in concert with a digital interface (e.g., dashboard) for health care providers }\end{array}$ \\
\hline $\begin{array}{l}\text { Coding and } \\
\text { reimbursement }\end{array}$ & $\begin{array}{l}\text { - Driven by product classification and their codes: } \\
\text { o NDC numbers: Pharmacy benefit or nonprescription } \\
\text { o NCPDP Product/Service Identifiers: Pharmacy benefit or nonprescription } \\
\text { o HCPCS or CPT codes: Medical benefit }\end{array}$ \\
\hline Delivery & - Software delivered via a mobile or Internet of Things device or hardware, medical device, service, or medication \\
\hline Subcategories & $\begin{array}{l}\text { - Adjunct to standard medical treatment } \\
\text { - Prevent, manage, or treat a medical disorder or disease } \\
\text { - Intended to improve clinical outcomes } \\
\text { - Reduce the risk of adverse events while delivering treatment }\end{array}$ \\
\hline
\end{tabular}

aThe term "SaMD" is defined as software intended to be used for one or more medical purposes that performs these purposes without being part of a hardware medical device. $C P T=$ Current Procedural Terminology; DTx=digital therapeutics; HCPCS = Healthcare Common Procedural Coding System; NDA=New Drug Application;

NDC = National Drug Code; NCPDP = National Council for Prescription Drug Programs; SaMD =software as a medical device

that the DTx is at least as safe and effective (i.e., substantially equivalent) to a legally marketed device. ${ }^{7}$ Different regulatory pathways may be needed for some DTx based on their unique features. For example, if a DTx does not meet the criteria for the 510(k) pathway, alternate pathways include De Novo and New Drug Applications (e.g., 505[b][2] combination products) in the United States. The FDA has also launched a Software Precertification Pilot Program as a component of the FDA Digital Health Innovation Action Plan to help inform the development of a future regulatory model. ${ }^{8}$

Participants observed that randomized controlled trials (RCTs) are still the gold standard for evaluations of biopharmaceutical products for regulatory approvals. While evidence may differ based on the clinical condition (e.g., such as rare disease) and type of therapeutic (software alone or software in combination with other treatments), sufficient evidence must be demonstrated pre-approval to ensure safety and efficacy. ${ }^{5}$ In addition, ongoing data to support modifications and improvements to the product, which follow good manufacturing practices (e.g., quality management systems change review process) and scientific validity, are key benefits of DTx.

RCTs might not be appropriate for DTx due to fundamental differences from pharmaceutical products, especially with respect to risk, frequent version enhancements, and personalization based on feedback loops. For example, iterative changes can be expected as a result of regular updates to software and operating platforms. A DTx with these ongoing updates may differ from the product initially reviewed by a regulatory entity. Therefore, strategies for evaluating DTx in the real world may include ongoing assessments of the products as updates are implemented. Thus, participants suggested that pragmatic trials and other innovative study designs, such as controlled cohort interrupted time series, would likely be important components of evaluating DTx.

The impact of product updates on approval processes should also be considered and may vary depending on the type 


\section{TABLE 3 Participant Observations Regarding Types of Evidence Desired for Evaluating DTx and} Determining Value

\begin{tabular}{|c|c|}
\hline Type of Evidence & Desired Details and Questions to Consider \\
\hline \multicolumn{2}{|c|}{ Required for market entry } \\
\hline Information security & - Compliance with HIPAA data security requirements \\
\hline Usability & $\begin{array}{l}\text { - Is there a level of health/digital literacy that is required to receive benefit from the DTx? } \\
\text { - Does the DTx operate as intended? For example, do all components of the software function as designed? }\end{array}$ \\
\hline \multicolumn{2}{|c|}{ Required for evaluation of value } \\
\hline $\begin{array}{l}\text { Clinical } \\
\text { effectiveness }\end{array}$ & $\begin{array}{l}\text { - Premarket: Must demonstrate safety and efficacy using standard endpoints prior to market authorization by regulatory authority } \\
\text { - What effect does the DTx have on clinically accepted, standard endpoints for the disease based on a measurable set of data? } \\
\text { - What is a clinically meaningful benefit/result? } \\
\text { - How do outcomes in the real world compare with those used for regulatory approval? } \\
\text { - What is the effect on patient satisfaction and quality of life? } \\
\text { - What level of evidence (e.g., RCT) is appropriate? } \\
\text { o Will depend on the health condition/medical claim }\end{array}$ \\
\hline $\begin{array}{l}\text { Engagement } \\
\text { (adherence) }\end{array}$ & $\begin{array}{l}\text { - Do patients use the DTx as intended in the real world? } \\
\text { - What "dosage" (level of sustained use over time) is required to achieve desired outcomes? } \\
\text { - Patient acceptance of the user interface/satisfaction of using the therapeutic } \\
\text { o Patient-reported outcomes can be used for assessment } \\
\text { - Potential for product updates to alter the user interface and affect engagement }\end{array}$ \\
\hline Safety & $\begin{array}{l}\text { - What are the adverse events in clinical trials? } \\
\text { - What are the adverse events in real-world use? } \\
\text { - How do adverse events compare to standard of care? } \\
\text { - What is the potential for harm? } \\
\text { o For example, what is the effect if the patient discontinues another therapy as a result of using the DTx? }\end{array}$ \\
\hline $\begin{array}{l}\text { Comparative } \\
\text { effectiveness }\end{array}$ & $\begin{array}{l}\text { - How does the DTx compare with other available treatments for the condition? } \\
\text { - The level of rigor required will depend on the potential for harm, availability of other therapies, and whether the DTx is considered } \\
\text { an adjunct or a replacement (i.e., a standalone treatment) }\end{array}$ \\
\hline Cost impact & $\begin{array}{l}\text { - Can cost avoidance be demonstrated? } \\
\text { - How does the DTx affect total cost of care? }\end{array}$ \\
\hline Data access & $\begin{array}{l}\text { - Who owns the data? } \\
\text { - Who has access to the data? } \\
\text { - How are the data used? }\end{array}$ \\
\hline Ongoing evaluations & - How will product updates be assessed to provide ongoing assurances of efficacy, safety, and usability? \\
\hline
\end{tabular}

of update, such as whether it changes the user interface (which could influence usability) or mechanism of action (e.g., change to a software algorithm or behavioral intervention).

Payer Evaluations. The National Institute for Health and Care Excellence (NICE) has published an Evidence Standards Framework for Digital Health Technologies in which they set out evidence standards for both the clinical and economic impact of new DTx. ${ }^{9}$ While this framework was developed for use in the United Kingdom, it can provide guidance to U.S. health care decision makers and payers around what evidence is needed from innovators for coverage.

Participants observed that ongoing value determinations for DTx will depend on comparative effectiveness data and health and economic outcomes data. There are several aspects of the DTx that will be important to payers when evaluating and determining coverage for a DTx. Beyond efficacy, payers are interested in assessments of patient acceptance of the DTx, where acceptance is analogous to adherence to a medication, which provides a potential measurement tool for patient engagement. Real-world evidence and patient-reported outcomes were also considered to be particularly important for informing payers and reevaluating coverage decisions. Logistical barriers, including patient access to a device and internet connectivity, must also be considered.

Participants suggested that managed care best practices for evaluating medications could potentially be adapted to accommodate various aspects of DTx and create a framework for evaluating DTx for coverage. 


\section{TABLE 4 Digital Therapeutics and Stakeholders-Opportunities and Issues Identified by Participants}

\begin{tabular}{|c|c|}
\hline Stakeholder & Needs and Issues \\
\hline $\begin{array}{l}\text { Patients and } \\
\text { caregivers }\end{array}$ & $\begin{array}{l}\text { - Desired information may include user reviews, consumer reports, bloggers, patient associations, and clinician endorsements } \\
\text { o The types of information that patients will desire about a DTx will likely depend on patient factors, including age and health con- } \\
\text { dition being treated } \\
\text { - Cost and coverage by third-party payers } \\
\text { - Ability to share data with health care providers, family members, or others to inform health care decision making } \\
\text { o Patients may share their data with others with the same condition through support groups and online communities } \\
\text { - Health literacy considerations } \\
\text { - Privacy of data }\end{array}$ \\
\hline Payers & $\begin{array}{l}\text { - Need a credible authority to determine the burden of proof that is required for providing recommendations upon which coverage } \\
\text { decisions can be based } \\
\text { - Need to identify which benefit is most appropriate for coverage of DTx products and how to integrate new products into existing } \\
\text { utilization management programs } \\
\text { - Need the ability to validate whether a DTx is effective in the real world } \\
\text { - Similar to the function of a P\&T committee, will need a process for internal assessment of DTx to evaluate each product and deter- } \\
\text { mine how it fits within the current treatment landscape } \\
\text { - Can use data from DTx to inform case management and expand care team outreach }\end{array}$ \\
\hline $\begin{array}{l}\text { Health care } \\
\text { providers }\end{array}$ & $\begin{array}{l}\text { - Providers have low levels of awareness of DTx, and few continuing education programs address DTx } \\
\text { - Need education and training for both practicing providers and those currently in training } \\
\text { - Need to understand liability concerns and administrative burdens } \\
\text { - Determine how to incorporate DTx in practice } \\
\text { o Workflow, patient education, and delivery of the product to the patient } \\
\text { - Need to establish best practices for using products and integrate DTx in guidelines, recommendations, protocols, and references } \\
\text { - Need best practices for using data } \\
\text { o Determining how the DTx could interact with EHRs, which data should be highlighted to providers, and when should a response } \\
\text { from the provider be triggered } \\
\text { o Identification of objective, actionable data that are presented in a useful format, such as a dashboard, that allows providers to } \\
\text { improve care } \\
\text { - Should consider that many patients do not have a regular primary care provider-could use telehealth and DTx to deliver treat- } \\
\text { ment, particularly for patients in rural or remote locations }\end{array}$ \\
\hline $\begin{array}{l}\text { Biopharmaceutical } \\
\text { companies and } \\
\text { product innovators }\end{array}$ & $\begin{array}{l}\text { - Likely will develop new paradigms for relationships among companies. Potential for many different financial arrangements among } \\
\text { biopharmaceutical companies and software developers } \\
\text { - Different levels of interaction depending on culture and philosophy of the companies involved and the disease state that is targeted } \\
\text { - Companies will use data from DTx for value-based arrangements, ongoing quality improvement, and research } \\
\text { - Need to consider who owns the data, who has access, when data should be deidentified, and how to comply with HIPAA }\end{array}$ \\
\hline Employers & $\begin{array}{l}\text { - Need to have a general understanding of the function of the DTx but do not require expertise } \\
\text { - Will rely on clinical experts to make recommendations } \\
\text { - Will be interested in the effect of the DTx on health, costs, and quality of life } \\
\text { - Patient engagement and satisfaction with the DTx based on objective data and patient-reported outcomes } \\
\text { - Availability of coverage through benefits including pharmacy or medical; options for coverage through HSA or FSA } \\
\text { - Data can inform risk sharing or value-based agreements }\end{array}$ \\
\hline
\end{tabular}

DTx = digital therapeutics; EHR = electronic health record; FSA = flexible spending account; HSA = health savings account; HIPAA = Health Insurance Portability and Accountability Act; PET = pharmacy and therapeutics.

\section{Stakeholder Needs and Perspectives of Value}

Participants identified needs and issues regarding DTx that are facing stakeholders, including patients, employers, payers, health care providers, product innovators, and biopharmaceutical companies (Table 4). Key issues facing each group focused on what types of assurances will be needed for the use of products.
For example, patients may be interested in the experiences of other patients, while payers and employers may be interested in demonstrated value. Further, stakeholders may also place higher value on some functions performed by DTx than others. For example, employers may be more interested than payers in the ability of a DTx to help a patient return to work. 
Issues around data use and security also affect several stakeholders. DTx allows for the collection of a substantial body of data about patient experiences, but integrating the data into clinical practice and applying the data to improve care may pose challenges. Patients may be most interested in using their data to inform their care, while some providers may desire systems that provide an alert when the DTx identifies an actionable event (e.g., an abnormal electrocardiogram reading). However, DTx that sends alerts to providers may increase the administrative burden and have liability issues if the provider does not respond to an alert. Integrating data from DTx into a patient's EHR can provide an opportunity to improve care and make information available to the health care team but faces many technical hurdles to become a reality across systems. Participants noted that DTx may be prescription or nonprescription, and different data integration requirements may affect each category.

\section{Reimbursement Considerations for DTx}

Beyond evaluating whether to provide coverage for DTx, payers must also determine which benefit should cover the product. Some participants suggested the creation of a standalone DTx benefit with its own specialized review process. However, others observed that trends in health care support integration, value-based purchasing, and increased focus on total cost of care. As a result, they argued against fragmentation of benefits and supported integrating DTx within existing benefit structures. They also suggested that benefits could allow patients to pay for DTx with individual health savings accounts or flexible spending accounts.

Participants generally favored inclusion of DTx within the existing pharmacy benefit because of the ability to apply managed care tools, such as a formularies and prior authorizations. This allows use of already-established processes whereby a health care organization identifies drug products and therapies that are the most medically appropriate and cost-effective to best serve the health interests of a given patient population. ${ }^{10}$ Further, in many cases, the outcome expected from a DTx is similar to what might be anticipated with a drug, making a DTx simply another therapeutic option.

Participants noted that DTx could be integrated into clinical guidelines and step therapy protocols, particularly for DTx that is intended to be used in place of available pharmacotherapies. The use of standard pharmacy product identifiers (e.g., National Drug Code numbers, National Council for Prescription Drug Programs codes, Generic Product Identifiers, Generic Code Numbers, or Unique Device Identifiers) will allow for coding of DTx within pharmacy benefit systems.

Participants noted that adding DTx to existing benefits may be a reasonable approach for commercial payers but that federal legislative changes are needed for DTx to be covered by Medicare and Medicaid. Nevertheless, they suggested that, in the interim, DTx could be covered indirectly through Medicare and Medicaid through value-based purchasing arrangements, such as bundled payments. DTx that has demonstrated value for improving patient outcomes and reducing total cost of care could be appropriate for a variety of value-based contracting arrangements, such as adherence-based contracts. The timeframe required to achieve anticipated benefits from DTx can affect which types of contracts would be most appropriate.

\section{Strategies for Integrating DTx in Health Care}

Participants stressed that it is important to create a solid foundation for the infrastructure around DTx within the current health care system. While recognizing that the field is rapidly evolving and that systems will need to be agile to support innovation, they also recognized the value of some degree of standardization to support effective and efficient uptake of multiple DTx simultaneously. Key issues facing the integration include how patients will access the products, the roles of health care providers in optimizing the use of DTx, and how the data that are generated by DTx are managed, including capture, integration, and storage. Participants noted that the integration of DTx into clinical practice guidelines for various treatment conditions would provide further validation of the value of the product and inform decision making.

There are several possible pathways for patients to access DTx. Many products require a prescription and will have their distribution to patients managed by providers, including pharmacists, specialty pharmacists, and patient-service centers. Others are available on a nonprescription basis and can be obtained through a wide range of platforms, including app stores and portals on employer websites. For prescription DTx, participants identified a need to integrate DTx into existing EHR and e-prescribing systems so that they could be seamlessly integrated into prescriber workflows.

Pharmacists have unique skills and expertise focused on optimizing medication treatment regimens that can be applied to support use of DTx. Managed care pharmacists supporting formulary drug systems are skilled in objectively appraising, evaluating, and selecting drugs for the formulary. Managed care pharmacists also have experience utilizing both subjective and objective patient information to monitor and direct medication use and could adapt these skills to assessments of DTx data. Community pharmacists can recommend DTx, receive results, help monitor patients' therapy, and counsel patients on the use of prescription drug use-related software so that patients understand the software component and use the product correctly. They can educate patients about the availability of these products and their use in conjunction with traditional prescription drugs. They can also direct patients to the appropriate coverage options (e.g., over-the-counter or medical coverage), as DTx may not consistently be processed through retail pharmacy channels. Overall, the importance of 
the pharmacist in promoting health care literacy was recognized as being particularly relevant with respect to DTx. With their extensive knowledge and skill, pharmacists will be well prepared to engage with DTx-specific education and support DTx integration in the health care system.

Parameters for data collection and sharing for DTx could differ depending on the DTx. However, key questions regarding cybersecurity and privacy must be addressed for products to be adopted and integrated with other aspects of the health care system. Appropriate levels of health care provider data access use should be considered. Participants noted that DTx can provide a rich source of data for patient-reported outcomes that can inform future product design. Additionally, use of such data to inform performance under value-based contracts and guide quality improvement efforts should be identified.

\section{Recommendations}

Participants identified a pressing need for expanded educational activities for health care providers regarding DTx. Currently, there are few continuing education activities about DTx, nor are these therapies generally discussed in the curricula for training health care professionals. Participants called for the creation of educational opportunities designed to inform all members of the health care team about DTx and how to integrate them within their practices. With additional DTx-specific training, pharmacists will be well positioned to be able to understand, manage, and deploy DTx to patients who need them. Additionally, DTx that demonstrates clinical effectiveness, especially comparative clinical effectiveness, can be included in clinical practice guidelines. Integration into clinical practice guidelines may be an effective way to encourage widespread use of DTx.

Participants recommended working with stakeholders to create a compendium that provides a listing of DTxs that have received regulatory approval for an efficacy claim. Additionally, participants identified the need to create authoritative resources to inform formulary and coverage determinations. They suggested the use of a system of evidentiary standards for DTx. They discussed the use of the NICE evidence standards framework for assessing DTx and also suggested the development of a system analogous to the Academy of Managed Care Pharmacy's (AMCP's) dossier system for biopharmaceutical products as a framework to support decision making. ${ }^{8}$ Participants observed that AMCP is considered an independent, authoritative, and credible source of information and could help manage the creation of criterion and protocols for DTx in the marketplace. They also recommended that AMCP continue to foster conversations among stakeholders and convene future gatherings and workgroups to advance the creation of effective systems and infrastructures.

\section{Forum Participants}

JEFFREY ABRAHAM, Vice President, Market Access and Trade, Aliki Interactive Labs; MICHAEL AMBROSE, PhD, Vice President, Head of Quality Institute and Head of Research \& Innovation, U.S. Pharmacopeia; TIMOTHY AUNGST, PharmD, Associate Professor of Pharmacy Practice, Massachusetts College of Pharmacy and Health Sciences University; RICK BARTELS, MBA, President, Digital Therapeutics Commercialization Consultants; MARK BINI, Vice President, Innovation and Member Experience, Express Scripts; JESSE BUSHMAN, MA, MALA, Senior Director, Health Policy, Juvenile Diabetes Research Foundation; AMBROSE CARREJO, PharmD, Principal, NACC Consulting; DUSTIN CARVER, Associate Director, Market Access Innovation, Novo Nordisk; ASTHA CHOPRA, Vice President, Cost of Care Management, Magellan Health; MEGAN CODER, PharmD, MBA, Executive Director, Digital Therapeutics Alliance; FELICIA FORMA, BSc, Director, Health Economics and Outcomes Research, Otsuka Pharmaceutical Development \& Commercialization, Inc.; CATHERINE GRAEFF, RPh, MBA, Managing Partner, Sonora Advisory Group; FRAN GREGORY, PharmD, MBA, Executive Director, Medical Account Management, Strategic Alliances E Advocacy, Sandoz; SCOTT HONKEN, PharmD, Vice President, Commercial Partnerships, Livongo; CONNIE HWANG, MD, MPH, Chief Medical Officer, Alliance for Community Health Plans; PAUL JEFFERY, PharmD, Director of Pharmacy, MassHealth; MIKE JOYCE, MBA, Associate Partner, McKinsey \& Company; THERESE JUDAY, RPh, Senior Director, Product Development, CVS Health; SEAN KARBOWICZ, PharmD, General Manager, Med Savvy; STEVEN KHELOUSSI, PharmD, Assistant Professor of Pharmacy Practice, Wilkes University/Geisinger Health Plan; MICHAEL LATAUSKA, Director, Digital Health, Boehringer Ingelheim; SNEZANA MAHON, PharmD, Vice President and General Manager, Express Scripts; YURI MARICICH, MD, Chief Medical Officer, Pear Therapeutics; DANIELLE MASSIE, PharmD, Pharmacy Manager, Business Development E Innovation, Moda Health; OWEN MCCARTHY, President, MedRhythms; ELISABETH OEHRLEIN, PhD, MS, Senior Director, Research \& Programs, National Health Council; SANIKA OGALE, PhD, Principal Health Economist, Genentech; MICHAEL PACE, MBA, VP, Global Head of Market Access, Value \& Evidence, Pear Therapeutics; BENJAMIN PARCHER, PharmD, MS, Manager, Strategic Market Access and Intelligence, Xcenda; CINDY PIGG, BSMT, BSPharm, MHA, FAMCP, Vice President, Managed Care and Business Development, Cardinal Health; CAROLINE POPPER, MD, MPH, Co-Founder and President, Popper and Company; EILEEN RODGERS, Director of Innovation, VITAL platform, Highmark Health; TIM RUDOLPHI, Chief Executive Officer, metaMe Health; BOB G. SCHULTZ, Health Economics and Outcomes Research Fellow, Takeda; JASON SHAFRIN, $\mathrm{PhD}$, Senior Director, Policy and Economics, Precision Xtract; PATRICK STONE, Vice President, Government Relations and Advocacy, Psoriasis Foundation; VALERIE SULLIVAN, Commercial Leader, MindSciences; SHEILA THOMAS, PharmD, RPh, Global Head, Patient Insights and Engagement Strategy, Sanofi, Inc.; RYAN TILTZ, RN, Innovation and New Product Development Lead, Clinical Engagement Services, OptumRx; F. RANDY VOGENBERG, BSPharm, PhD, FASHP, Principal and Board Chair, Institute for Integrated Healthcare, Employer-Provider Council of Hospital Quality Foundation; MARGARET WONG, MBA, Director, Managed Markets Marketing, Gilead Sciences; BONNIE ZIEGLER, Senior Director, Global Marketing - Digital Health, Teva Pharmaceuticals.

CORRESPONDENCE: Cynthia Reilly, MS, BSPharm, Chief Operating Officer, AMCP, 675 N. Washington St., Alexandria VA 22314.

E-mail: creilly@amcp.org. 


\section{DISCLOSURES}

This AMCP forum was sponsored by Akili Interactive Labs, Boehringer Ingelheim, Genentech, Gilead, Lovongo, MedRhythms Therapy, Merck \& Co., metaMe Health, MindSciences, Novo Nordisk, Otsuka Pharmaceutical, Pear Therapeutics, Precision for Value, Sandoz, Sanofi, Takeda, Teva Pharmaceuticals, and Xcenda. These proceedings were prepared as a summary of the forum to represent common themes; they are not necessarily endorsed by all attendees nor should they be construed as reflecting group consensus. Cynthia Reilly, MS, BSPharm, correspondent, is an employee of $\mathrm{AMCP}$ and declares no conflicts of interest, real or apparent, with any product or service mentioned in this report.

\section{ACKNOWLEDGMENTS}

The AMCP Partnership Forum "Digital Therapeutics: What Are They and Where Do They Fit in Pharmacy and Medical Benefits?" was moderated by Joseph Honcz, RPh, MBA, Vice President, Director-Access Experience Team, Precision for Value. This proceedings report was written by Judy Crespi Lofton, Medical Writer and Consultant, JCL Communications.

\section{REFERENCES}

1. U.S. Food and Drug Administration. Digital health. Available at: https:// www.fda.gov/medical-devices/digital-health. Accessed February 21, 2020.

2. Digital Therapeutics Alliance. Digital therapeutics: combining technology and evidence-based medicine to transform personalized patient care. 2018. Available at: https://www.dtxalliance.org/wp-content/uploads/2018/09/DTAReport_DTx-Industry-Foundations.pdf. Accessed February 21, 2020.
3. World Health Organization. Classification of digital health interventions vl. 0: a shared language to describe the uses of digital technology for health 2018. Available at: https://apps.who.int/iris/handle/10665/260480. Accessed February 21, 2020.

4. Mathews SC, McShea MJ, Hanley CL, et al. Digital health: a path to validation. NPJ Digit Med. 2019;2:38.

5. Centre for Evidence-Based Medicine. Oxford Centre for Evidence-based Medicine-levels of evidence. March 2009. Available at: https://www. cebm.net/2009/06/oxford-centre-evidence-based-medicine-levels-evidencemarch-2009/. Accessed February 21, 2020.

6. Mobile Health News. New market guidances, regulatory pathway change proposals close out 2018 for FDA. December 21, 2018. Available at: https:// www.mobihealthnews.com/content/new-market-guidances-regulatory-pathway-change-proposals-close-out-2018-fda. Accessed February 21, 2020

7. U.S. Food and Drug Administration. Digital health innovation action plan. Available at: https://www.fda.gov/media/106331/download. Accessed February 21, 2020.

8. U.S. Food and Drug Administration. Digital health software precertification program. Available at: https://www.fda.gov/medical-devices/digitalhealth/digital-health-software-precertification-pre-cert-program. Accessed February 21, 2020.

9. National Institute for Health and Care Excellence. Evidence standards framework for digital health technologies. March 2019. Available at: https:// www.nice.org.uk/Media/Default/About/what-we-do/our-programmes/ evidence-standards-framework/digital-evidence-standards-framework.pdf. Accessed February 21, 2020

10. American Society of Health-System Pharmacists. Principles of a sound drug formulary system. Available at: https://www.ashp.org/-/media/assets/ policy-guidelines/docs/endorsed-documents/endorsed-documents-principles-sound-drug-formulary-system.ashx. Accessed February 21, 2020. 